Economía, Sociedad y Territorio, vol. vI, núm. 22, 2006, 497-533

\title{
Transformación social y territorial del sistema agrario ejidal en la región del Alto Lerma
}

\author{
María Estela Orozco Hernández* \\ María Teresa Sánchez Salazar**
}

\begin{abstract}
This paper presents empirical evidence that configure the process of social and territorial transformation in the agrarian common land (ejido) system in the region of Alto Lerma. The change trends are analysed in the farming systems, the land usage and the occupation and social organisation of the population. The sensibility to change is the collective response built from the various individual strategies, which are developed by each ejidatario (common land owner) to face the deterioration in their way of life. We have analysed the results obtained from four hundred and thirty-nine questionnaires from selected plots in the 2001-2002 agricultural year.
\end{abstract}

Keywords: regional transformation, agrarian system, Alto Lerma region.

\section{Resumen}

En este trabajo se exponen evidencias empíricas que configuran el proceso de transformación social y territorial del sistema agrario ejidal en la región del Alto Lerma. Las tendencias de cambio se analizan en los sistemas de cultivo, en el uso de la tierra, en la ocupación y en la organización social de la población. La sensibilidad al cambio es la respuesta colectiva construida a partir de estrategias individuales variadas, las cuales son desarrolladas por cada ejidatario para enfrentar el deterioro de su forma de vida. Se analizan los resultados obtenidos a partir de 439 cuestionarios aplicados en parcelas seleccionadas en el año agrícola 2001-2002.

Palabras clave: transformación regional, sistema agrario, región del Alto Lerma.

* Facultad de Planeación Urbana y Regional de la Universidad Autónoma del Estado de México. Correo-e: eorozcoh6@hotmail.com y maresor@uaemex.mx.

*: Instituto de Geografía de la Universidad Nacional Autónoma de México. Correo-e: mtss@igiris.igeograf.unam.mx. 


\section{Introducción}

Las escasas reflexiones sobre el papel que juegan las transformaciones de las sociedades rurales locales en la evolución del conjunto (Ruellan y Godard, 1994: 251) llevan a ubicar los estudios de caso en el campo de sus relaciones con el resto de la estructura económica, social y territorial que constituye su entorno (Pradilla, 2002: 7). En ese contexto, el sistema agrario ejidal de la región del Alto Lerma se comprende como un conjunto de elementos físico-naturales, histórico-sociales, culturales, económicos y políticos cuya interacción y organización regula las formas de explotación de la tierra en el escenario más reciente del capitalismo mundial (Orozco, 2003: 13, 84).

Las evidencias sobre la transformación social y territorial del sistema agrario en cuestión se sustentan en cuatro planteamientos: el primero se refiere a la consideración de que la organización ejidal se encuentra profundamente deteriorada en el país debido, entre otros argumentos: a la modificación de su función como instrumento de organización política y unidad productiva (Hernández, 1994: 202); al surgimiento de nuevos actores y al envejecimiento de los ejidatarios, lo que tiende a diversificar y erosionar la realidad ejidal (Pérez, 1994: 225); al escaso incremento de la inversión en las actividades productivas ejidales, y a las restricciones motivadas por la reducción de los subsidios al campo, que limitan la posibilidad de hacer negocios a partir de la libre asociación y la compra-venta de tierras (OCDE, 1997: 19). El segundo expone que la permanencia del ejido en la coyuntura política actual, no lo define como un fenómeno global, pero sí como un hecho histórico inscrito en el contexto global (Bueno, 2000: 7-9). En este escenario, las economías ejidales responden de manera general a dos tipos de objetivos: por un lado, producir y acumular y, por el otro, proveerse de alimentos y garantizar la reproducción de la familia. En la relación económica de estrategia campesina-mercado, se perfilan los objetivos y la distribución de los beneficios, ello significa posibilidad de vida y permanencia para las nuevas sociedades agrarias ejidales (Orozco, 2003: 282). El tercero cuestiona la importancia que se da a la influencia de los factores externos sobre los cambios que experimentan las sociedades y economías rurales, lo cual minimiza el papel de los sujetos sociales como partícipes conscientes o inconscientes de la transformación de su forma de vida (Orozco, 2005: 8). Y, finalmente, el cuarto planteamiento sostiene que los procesos 
regionales y locales pueden no sólo darle una connotación particular a los procesos regionales, sino también pueden contrarrestar, acelerar o retardar aquellos procesos (De la Garza, 1994: 52). La articulación global-local se manifiesta a través de los canales que la posibilitan-variables internas sensibles a los comportamientos externos-; por lo tanto, los cambios no se transmiten de manera lineal a todo espacio-tiempo nacional, regional o local, sino que las características de los procesos de transformación pueden darle un carácter particular a los procesos generales (Hiernaux, 1994: 35). Ello significa que el ritmo y la velocidad del cambio dependen no sólo de la sensibilidad de los lugares, sino también, y en forma determinante, de las acciones y decisiones de los agentes locales y regionales.

Desde la perspectiva del actor social, los procesos agrarios de cambio se manifiestan como formas emergentes y socialmente construidas cuyos significados son negociados por los diferentes actores involucrados en su construcción, reproducción y transformación. En esos procesos destaca la heterogeneidad y su significado social, las situaciones de interfase donde los mundos de los actores se entrelazan, se acomodan o chocan entre sí, y las prácticas organizativas particulares encaminadas a efectuar el cambio (Long, 1998: 50, 54).

El objetivo de este trabajo es caracterizar, con base en una serie de evidencias empíricas, las rupturas y continuidades que configuran el proceso de transformación social y territorial del sistema agrario ejidal en la región del Alto Lerma.

\section{Metododología}

El presente trabajo se inscribe en el proyecto denominado "Sistema agrario ejidal en el contexto de la globalización: el caso de la cuenca alta del río Lerma, México”, el cual fue financiado a lo largo de cuatro años (2000-2004) por el Consejo Nacional de Ciencia y Tecnología (Conacyt).

Para explorar las evidencias de cambio en el sistema agrario ejidal en la región del Alto Lerma se realizaron 439 entrevistas en 160 ejidos seleccionados en el año agrícola 2001-2002. En la estimación de la muestra se utilizaron la fórmula y los parámetros sugeridos en poblaciones finitas (Sierra, 1995; cuadro 1). El universo de la muestra se compuso de 413 ejidos, distribuidos en tres unidades territoriales: el sector sur con 22 municipios, el sector centro con siete, y el sector norte con tres (GEM, 2000; figura I). 


\section{Cuadro 1}

Fórmula utilizada para calcular las unidades de muestreo

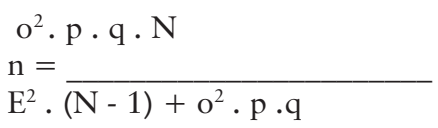

$$
\begin{aligned}
& \mathrm{N}=\text { tamaño del universo } \\
& \mathrm{n}=\text { tamaño de la muestra } \\
& \mathrm{o}^{2}=\text { intervalos de confianza } \\
& \mathrm{p}, \mathrm{q}=\text { varianzas } \\
& \mathrm{E}^{2}=\text { error de la muestra }
\end{aligned}
$$

\begin{tabular}{|c|c|c|c|}
\hline \multicolumn{4}{|c|}{ Superficie municipal por subregión } \\
\hline Subregiones & Hectáreas & $\mathrm{Km}^{2}$ & $\%$ \\
\hline Sur & 222.386 .6 & $2,223.866$ & 37.58 \\
\hline Centro & 271,135 & $2,711.350$ & 45.82 \\
\hline Norte & 98,101 & 981.01 & 16.58 \\
\hline Región & $591,622.6$ & 5916.226 & 99.98 \\
\hline
\end{tabular}

\section{Figura I}

\section{Ubicación de la región del Alto Lerma, México}
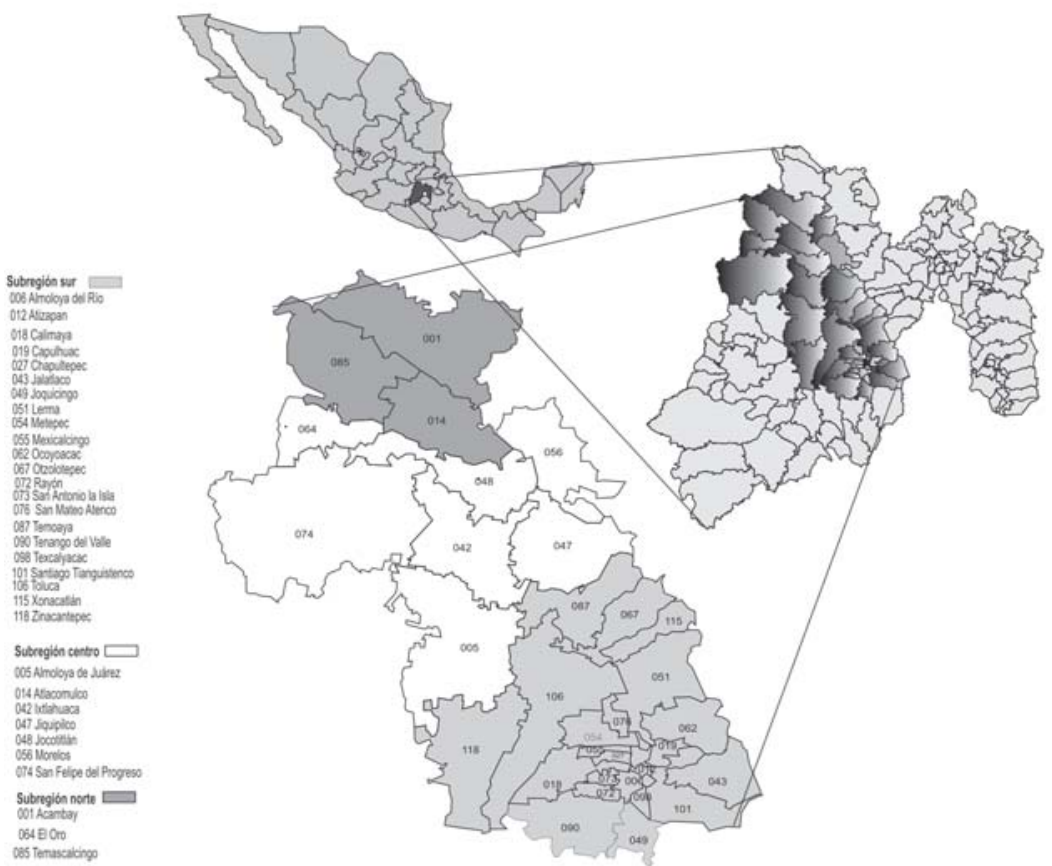
(mimeo).

El nivel de confianza fue de $95.5 \%$, el error asignado fue de $10 \%$, y el índice de variación en el nivel de confianza fue de dos sigmas o intervalos. Con base en el listado de ejidos y comunidades agrarias (INEGI, 1991) -con el listado de ejidos y comunidades se planearon el VII Censo Agrícola, Ganadero y Ejidal y el Programa de Certificación de Derechos Ejidales y Solares Urbanos (Procede) en el Estado de México- se procedió a seleccionar los eji- 


\section{Cuadro 2 \\ Resumen de la muestra total analizada en la región del Alto Lerma}

\begin{tabular}{lcccccccc}
\hline Curso & $\begin{array}{c}\text { Unidades } \\
\text { de produc- } \\
\text { ción que } \\
\text { usan tec- } \\
\text { nología }\end{array}$ & $\begin{array}{c}\text { Error } \\
\text { tral }\end{array}$ & $\begin{array}{c}\text { Total } \\
\text { cuestio- } \\
\text { narios }\end{array}$ & $\begin{array}{c}\text { Fracción } \\
\text { uni- } \\
\text { verso }\end{array}$ & $\begin{array}{c}\text { Universo } \\
\text { de ejidos }\end{array}$ & $\begin{array}{c}\text { Error } \\
\text { mues- } \\
\text { tral }\end{array}$ & $\begin{array}{c}\text { Total } \\
\text { ejidos }\end{array}$ & $\begin{array}{c}\text { Fracción } \\
\text { del } \\
\text { universo }\end{array}$ \\
\hline Alto & 31,713 & 8.0 & 155 & 0.40 & 139 & 10 & 58 & 41.7 \\
Medio & 35,974 & 8.0 & 156 & 0.43 & 223 & 10 & 69 & 30.9 \\
Bajo & 10,003 & 10 & 99 & 0.9 & 51 & 10 & 34 & 66.6 \\
Total & 77,690 & & 410 & 0.52 & 413 & & 161 & 38.9 \\
\hline
\end{tabular}

Fuente: Elaboración propia.

dos legalmente reconocidos, excluyendo otras formas de organización agraria; cada ejido elegible debía desarrollar actividad agrícola (cuadro 2). En la estimación de la muestra de cuestionarios, el universo se compuso de las unidades de producción ejidal que usan tecnología (INEGI, 1994); ${ }^{1}$ el nivel de confianza, el índice de variación y el error de la muestra se registran en el cuadro 1. Finalmente se aplicaron dos cuestionarios en cada ejido seleccionado y uno más en $73 \%$ de los mismos, hasta cubrir el tamaño de la muestra.

\section{Organización del sistema agrario ejidal}

La región del Alto Lerma constituye el escenario de complejos procesos de expansión y concentración poblacional, urbana e industrial, y de una significativa actividad agrícola sostenida en el cultivo de maíz. Comprende una superficie de $5,916 \mathrm{~km}^{2}$ distribuida en 32 municipios, y sus componentes físico-geográficos principales son el valle de Toluca y el valle de Atlacomulco-Ixtlahuaca. La población asciende a 2’396,677 habitantes, 68\% de los cuales se concentran en municipios metropolitanos como $\mathrm{Zi}$ nacantepec, Toluca, Metepec, Lerma, San Mateo Atenco, Xonacatlán y Ocoyoacac (INEGI, 2000).

${ }^{1}$ El trabajo toma como referente regional el VII Censo Agrícola, Ganadero y Ejidal (INEGI, 1994). La temporalidad de los datos se ubica en el contexto de la estrategia neoliberal del cambio estructural -puesto en marcha en el periodo 1983-1987-, el cual comprendió un programa de liberalización del sector agropecuario: 1) la reducción del intervencionismo gubernamental en el desarrollo sectorial; 2) la apertura comercial externa que remató en la inclusión del sector agropecuario en el Tratado de Libre Comercio de América del Norte, y 3) la reforma al Artículo 27 Constitucional y de su ley reglamentaria (Calva, 1996: 17, 39). Los datos se actualizan en lo posible con el Censo Ejidal 2001 (INEGI, 2003). 
Figura II

Región del Alto Lerma, México.

Distribución de la propiedad social, 2001

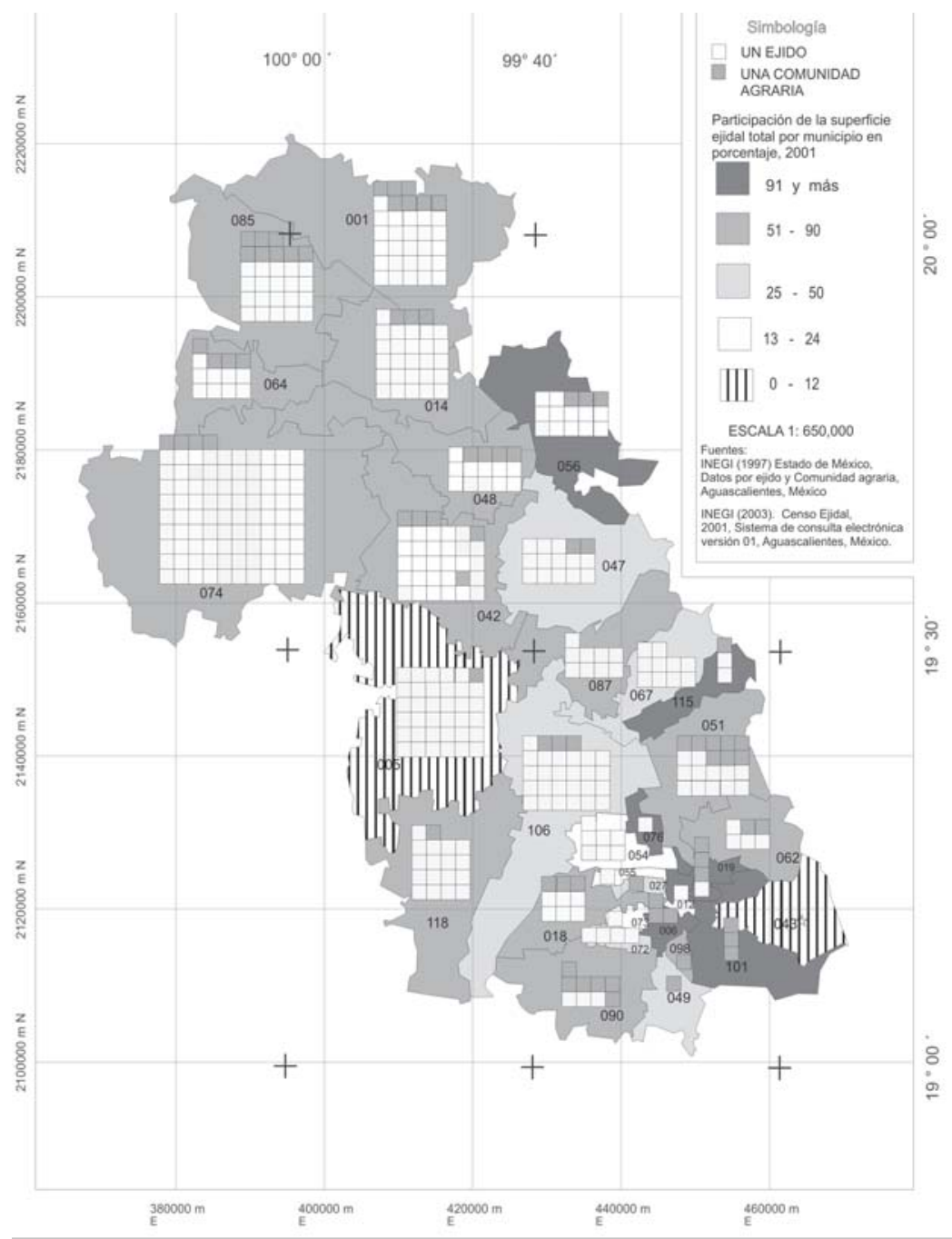

La agricultura ocupa 678,654 hectáreas; de dicha superficie, $41 \%$ es de temporal, $9 \%$ de riego y $50 \%$ de riego-temporal, y el maíz ocupa 93\% de la superficie sembrada (Sagar, 2001). La región concentra $37 \%$ de los ejidos y las comunidades agrarias del Estado de México, 68\% de su superficie total es de propiedad social, y aglutina a 157,226 ejidatarios y comuneros (INEGI, 2003; figura II). 
La distribución de las propiedades sociales permite identificar, por una parte, a los ejidos localizados en las tierras agrestes de la porción serrana de la región del Alto Lerma, y, por la otra, a los ejidos ubicados en la zona de los valles. En esa área se presenta la mayor conflictividad urbana, industrial y agraria; su potencial agropecuario y forestal se ve cada vez más disminuido por la competencia permanente con los usos del suelo industrial y habitacional, los cuales tienen un valor estratégico para la economía regional, en tanto que el valor de uso de la tierra agrícola pierde importancia ante las necesidades de una población urbana en expansión.

\subsection{Derechos agrarios y tamaños de las parcelas}

Por su antigüedad, de entre los entrevistados destacan los que se reconocen con más de cuarenta y cinco años como ejidatarios; un segundo grupo está conformado por aquellos que tienen menos de diez años de serlo (figura III).

Figura III

Región del Alto Lerma, México. Antigüedad de los ejidatarios

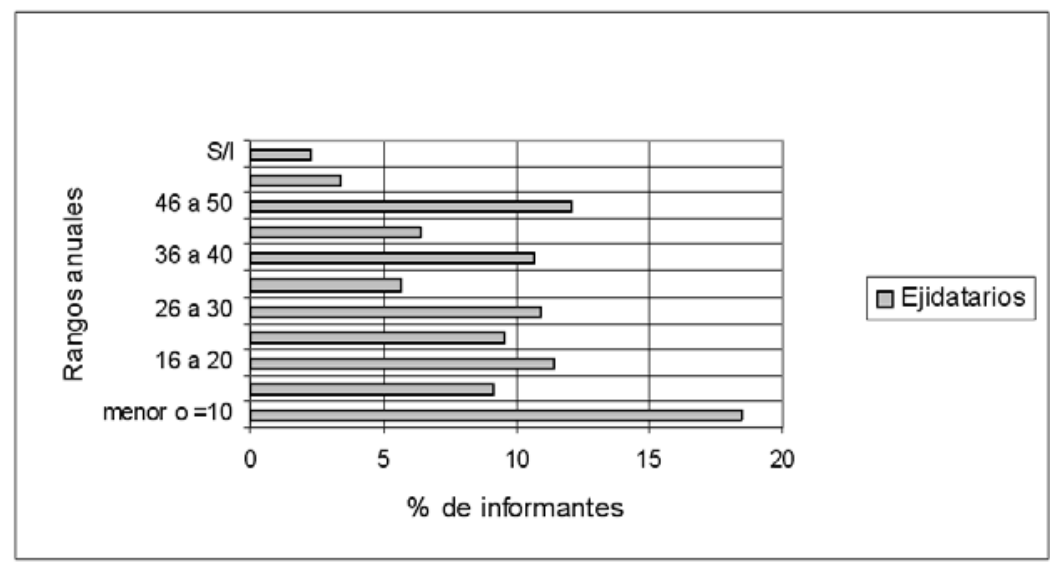

Fuente: Elaboración propia, 2001-2002.

De los ejidatarios, $87 \%$ cuenta con certificado de derechos agrarios y $58 \%$ con certificado parcelario. La reconstrucción del proceso de certificación muestra que el inicio de ese proceso de regularización de la tierra ocurrió durante el periodo 1920-1929, y se intensificó paulatinamente en las décadas siguientes, hasta alcanzar las más altas tasas de certificación entre 1970 y 1989 


\section{Figura IV \\ Región del Alto Lerma, México. Certificación de la tenencia de la tierra ejidal}

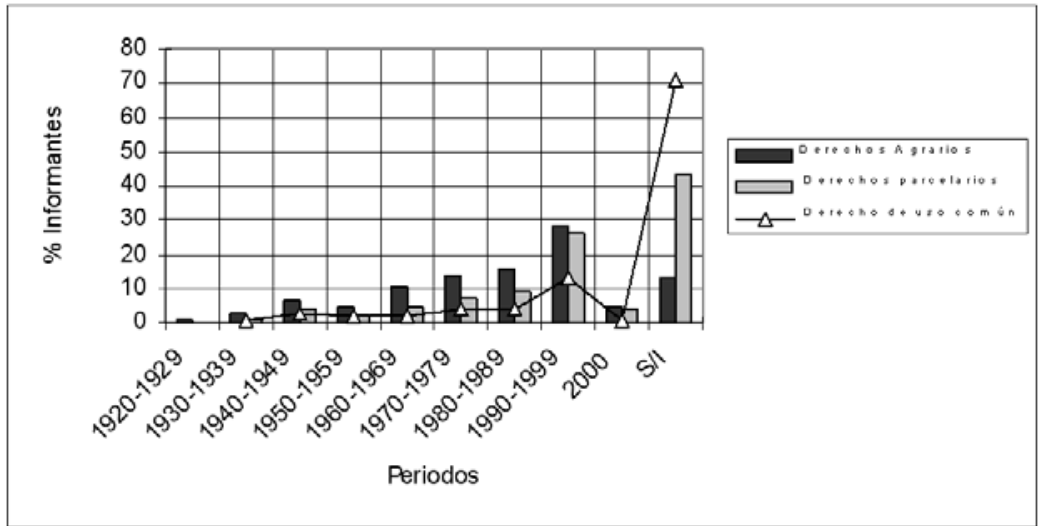

Fuente: Elaboración propia, 2001-2002.

(29.6\%) y entre 1990 y 2000 (32.42\%). En esa última década, el detonante de la regularización de la tierra ejidal fue el Procede, cuya cobertura de medición en las parcelas muestreadas fue de $65 \%$ (figura IV).

Aun cuando no se conocen en su totalidad las implicaciones del Procede, de acuerdo con la información obtenida en campo, la certificación de la tierra es importante para dar seguridad a la familia. Sin embargo, la medición y la certificación no han mejorado la situación económica de la población ejidal ni las condiciones en las que se cultiva la tierra; por el contrario, han promovido el fraccionamiento de la tierra en favor de los hijos de ejidatarios ${ }^{2}$ o bien la venta de fracciones de terreno debido al deterioro de la economía ejidal.

En cuanto al tamaño de las parcelas ejidales, tanto la información censal (INEGI, 2003) como la información de campo confirman que más de $90 \%$ de éstas tienen una superficie no mayor a cinco hectáreas. El carácter minifundista de las parcelas ejidales

2 Previo a la instrumentación del nuevo marco jurídico agrario y del Procede, la cesión no formal del derecho de usufructo de la tierra a los hijos se realizaba a la muerte del ejidatario; ello permitía preservar las dinámicas productivas donde la toma de decisiones se daba al interior de la unidad doméstica. Las reformas posteriores propician que los productores con mayor poder adquisitivo adquieran más tierra mediante la venta o la renta directa de parcelas de su misma comunidad (ya sea para mantener un cultivo básico o para aventurarse en otro tipo de cultivos). Ello puede resultar en economías de escala para aquellos que pueden acaparar la tierra, pero representa una pérdida del bien para los que la rentan o la venden (Cortés y Díaz, 2005: 12). 


\section{Figura $v$}

Región del Alto Lerma, México. Importancia relativa de los rangos de tamaño de las parcelas ejidales $(\%)$

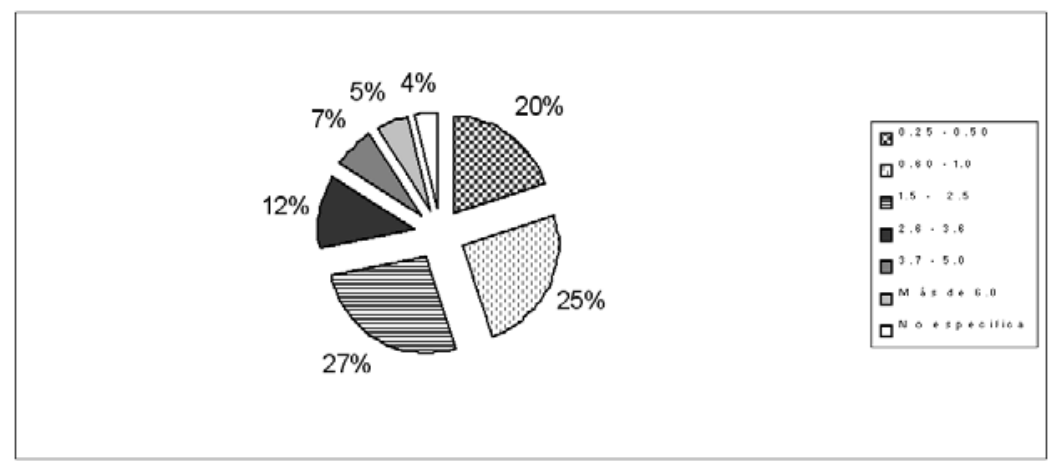

Fuente: Elaboración propia, 2001-2002.

constituye el rasgo característico de las economías campesinas, en donde el criterio de optimización es el equilibrio entre la satisfacción de las necesidades familiares y la intensidad del trabajo (Chayanov, 1974; figura v).

Los poseedores de parcelas de mayor tamaño son ejidatariosarrendatarios que rentan las tierras a vecinos colindantes para aumentar el área de la superficie de cultivo. Cuando se trata de cultivar maíz, el tamaño de los predios sigue siendo una garantía para asegurar un volumen mínimo de producción.

\subsection{Apoyo financiero}

En 1991, la estructura de apoyo al campo estaba encabezada por el Banco de Crédito Rural (Banrural) y otras instituciones financieras; en ese año solamente $6 \%$ de los ejidatarios de la región recibieron crédito y seguro. La nueva estructura financiera se delineó en 1994 en torno al Programa de Apoyo al Campo (Procampo). En la muestra, más de $95 \%$ de los ejidatarios no recibieron apoyo financiero (crédito y seguro), y solamente 65\% de los entrevistados recibió apoyo del Procampo (figura vi).

El abatimiento del financiamiento productivo y la limitada cobertura del Procampo en la región del Alto Lerma han traído como consecuencia una profunda descapitalización, agudizada por el requisito de tener que dar en prenda las propiedades como aval físico del préstamo, lo cual ha provocado desaliento entre 
Figura VI

Región del Alto Lerma, México. Montos de apoyo del Procampo en los ejidos (pesos)

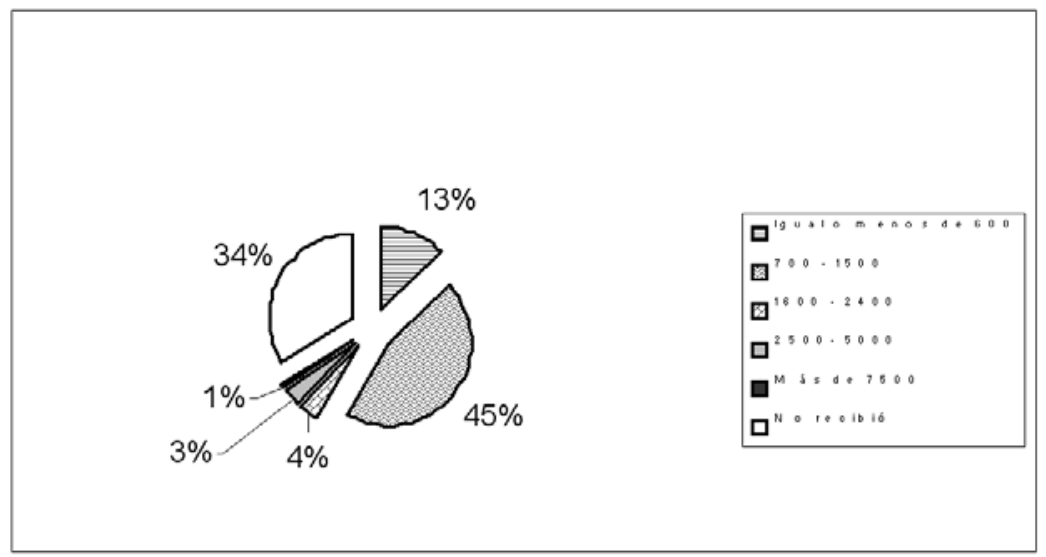

Fuente: Elaboración propia, 2001-2002.

los ejidatarios para solicitar el apoyo, y temor ante la posibilidad de perder su patrimonio. ${ }^{3}$

\section{Sistema de producción de maíz}

\subsection{Superficie de labor y rendimientos}

En el ámbito local, como resultado del muestreo de campo se registraron 1,130 terrenos con una superficie de 990.25 hectáreas, de las cuales $26.12 \%$ cuenta con riego, y poco más de $70 \%$ de la superficie es de temporal. Es común la alternancia de ciclos agrícolas en los que se tienen prolongadas sequías, así como la anticipación del periodo de lluvias, en ocasiones torrenciales. Esos fenómenos meteorológicos conducen a la pérdida total o parcial de la cosecha.

Un sector de ejidatarios siembra el maíz, sin más cuidado que las labores previas a la temporada de lluvia (abril-mayo), mientras que otro sector realiza los cuidados y la inversión necesarios para garantizar la producción. Los costos aumentan por la incor-

${ }^{3}$ En general, las políticas macroeconómicas de ajuste estructural han tendido a eliminar los subsidios del crédito agrícola (De Grandi, 1996: 38). En México, el nuevo esquema financiero está concebido para atender la demanda crediticia de la agricultura desarrollada y con posibilidades de desarrollo; no hay mecanismos para encarar los requerimientos diversos de los campesinos de escala pequeña, los cuales se incorporan cada vez más al trabajo no agrícola para obtener recursos económicos. 
Figura VII

Región del Alto Lerma, México.

Ciclo económico del maíz, 2002-2003

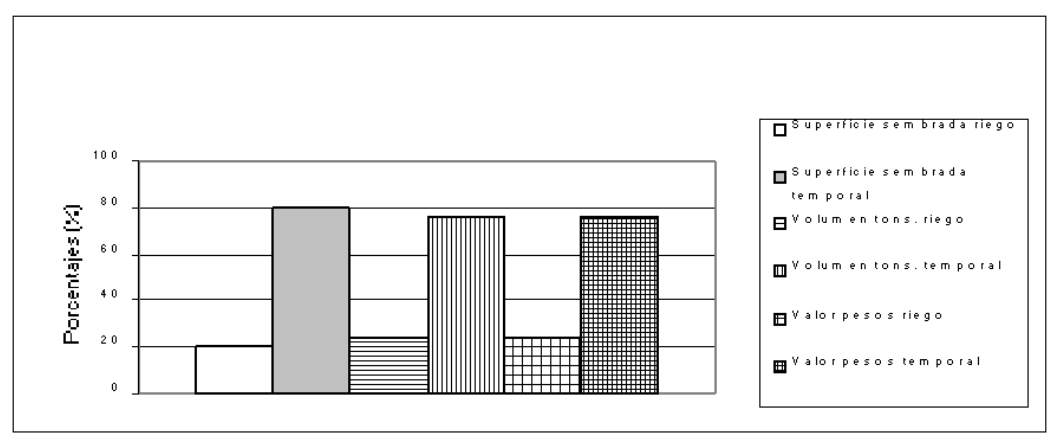

Fuente: Elaboración propia con base en INEGI (2004).

poración de mano de obra remunerada y por la compra de insumos agrícolas, así como por la cantidad y calidad de las labores culturales realizadas antes y después de la siembra y en la cosecha. Las variaciones técnicas y productivas en el manejo de la tierra se encuentran fuertemente determinadas por los ingresos no agrícolas.

En el ciclo agrícola 2002-2003 (INEGI, 2004), la región del Alto Lerma aportó a la entidad 50\% de la superficie sembrada de maíz, $52 \%$ del volumen de la producción, y $46 \%$ del valor de la producción. Ello confirma la importancia maicera de la región, sostenida fundamentalmente en la producción de temporal (figura VII). El rendimiento medio del maíz en riego fue de cuatro toneladas por hectárea, y el del maíz de temporal, de 3.2 toneladas por hectárea, mientras que la productividad económica, tanto en riego como en temporal, corresponde a un monto ligeramente superior a los 1,300 pesos por tonelada.

En la muestra de campo se identificó que en parcelas adecuadamente atendidas, se obtuvieron rendimientos de más de tres toneladas por hectárea; es decir, que aquellos ejidatarios que tienen más de seis hectáreas y hasta 10, obtienen una producción de 18 y hasta 30 toneladas en un ciclo productivo. Aun cuando varían los rendimientos de un predio a otro, el problema central de la producción de maíz no es la productividad, sino los bajos precios en el mercado, los cuales colocan al Alto Lerma como una de las regiones perdedoras como resultado de los cambios y reestructuraciones operadas en el sector agropecuario nacional. 


\subsection{Mecanización, semillas y fertilizantes químicos}

Cuarenta y uno por ciento de los ejidatarios entrevistados utiliza tractor, 26\% usa sólo yunta, y 28\% emplea ambos tipos de fuerza. La elección de uno u otro tipo de equipo depende de las condiciones del terreno. En los valles, donde los terrenos son planos, se utiliza el tractor, y en las áreas donde los terrenos presentan cierta pendiente se emplea la yunta. Solamente $20 \%$ de los ejidatarios emplean desgranadoras y hacen uso de instalaciones como empacadoras y bodegas.

Respecto a la propiedad de la tecnología utilizada, en 60\% de los casos muestreados el equipo es rentado, y en $23 \%$ se trata de equipo propio. Los ejidatarios que poseen tractor o yunta comúnmente los rentan a otros ejidatarios para agilizar los trabajos inherentes a la siembra. Esa situación identifica la presencia en la región en estudio del fenómeno de la maquila agrícola, la cual se ha convertido en una actividad subsidiaria que ha adquirido una importancia estratégica (Palacios et al., 2005: 1). Para los ejidatarios representa la posibilidad de ocuparse en otras actividades económicas que les proporcionan mayores ingresos que la propia actividad agrícola.

En relación con el empleo de nuevas semillas, es común que el ejidatario combine la tecnología tradicional con la moderna de forma empírica, y que no se cuente con asistencia técnica formal. La información del ciclo agrícola 2001-2002 muestra que ese insumo agrícola se utilizó en $1.3 \%$ de la superficie sembrada en la región del Alto Lerma (INEGI, 2004). En la muestra encuestada, en el mismo ciclo agrícola se registró que $87.91 \%$ de los ejidatarios empleó semilla criolla, $8.87 \%$ usó semilla mejorada, y solamente $1.35 \%$ de ellos utilizó semilla híbrida (figura viII).

La adopción de las nuevas semillas ha sido un proceso lento; el periodo de 1991 a 2000 destaca como el más relevante y coincide, en primer término, con la política de reconversión tecnológica, cuyo instrumento principal ha sido el Programa de Transferencia de Tecnología operado por medio de la fundación Produce ${ }^{4}$ y que

${ }^{4}$ Las fundaciones Produce, A.c. se instituyen como el eje de la reconversión tecnológica del Programa de la Alianza para el Campo en 1995. A diferencia de otras entidades, en el Estado de México esa fundación no opera de manera autónoma. Los proyectos de investigación y transferencia de tecnología son definidos por el Instituto de Investigación y Capacitación Agropecuaria, Acuícola y Forestal del Estado de México (Icamex), creado por mandato constitucional en julio de 1987. La fuerte componente estatal del programa de transferencia e investigación tecnológica en la entidad se define a partir del presidente de la fundación para el Estado de México; ese papel lo desem- 


\section{Figura VIII}

Región del Alto Lerma, México.

Importacia relativa de los periodos de adopción de semillas mejoradas e híbridas en las parcelas muestreadas (\% del total)

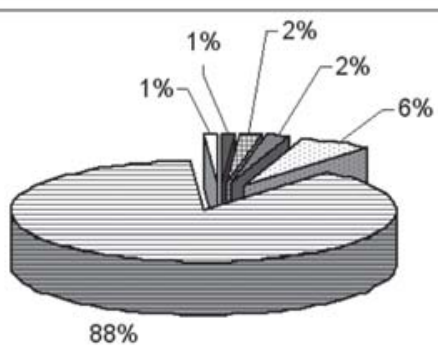

\begin{tabular}{|l|}
\hline \\
$\square 1961-1970$ \\
$\square 1981$ - 1990 \\
$\square 1991$ - 1995 \\
$\square 1996$ - 2000 \\
$\square$ Emplea semilla criolla \\
$\square$ No especifica
\end{tabular}

Fuente: Elaboración propia, 2001-2002.

se ejecuta en los Distritos de Desarrollo Rural (DDR $)^{5}$ con apoyo federal y estatal (Sagar, 2001); y, en segundo término, con la presencia de las comercializadoras de semilla transnacionales como ASGROW y Monsanto. Se estima que el impacto de esas empresas en la región ha sido mínimo, ya que la estrategia de colocar parcelas experimentales no ha funcionado, pues tanto en la porción sur como en la porción media del Alto Lerma, las lluvias son torrenciales y con frecuencia la semilla se pudre. ${ }^{6}$

Las semillas híbridas más utilizadas por los ejidatarios al momento de la encuesta fueron la $\mathrm{H}-50$ y la $\mathrm{H}-30$, ambas proporcionadas por la Secretaría de Desarrollo Agropecuario de la entidad (Sedagro) por medio del programa "Kilo por Kilo". De acuerdo con la opinión de los entrevistados, ese tipo de semillas

peña oficialmente el director del Icamex, cuya función se centra en discutir y acordar la viabilidad de los proyectos estatales en el seno de las reuniones de la Coordinadora Nacional de las Fundaciones Produce, A.C. (Cofupro, 2005: 1).

${ }^{5} \mathrm{El}$ antecedente de los DDR se encuentra en la adecuación de los distritos de riego y temporal de la otrora Secretaría de Agricultura y Recursos Hidráulicos (SARH). En 1995, esa secretaría cambió su nombre a Secretaría de Agricultura, Ganadería y Desarrollo Rural (Sagar), y su regionalización, para fines de coordinación de las zonas de riego y temporal, se estableció sobre la base de los DDR. En el año 2000, la Sagar incorporó al sector de la pesca (Orozco et al., 2004: 34). La Ley de Desarrollo Sustentable 2002, con base en los DDR instituyó como parte de la estructura ejecutiva del Desarrollo Rural Sustentable a los Consejos Distritales de Desarrollo Rural (CEDRSSA/DG/IR/008/05).

${ }^{6}$ Las semillas o razas mejoradas son específicas por estrato ambiental, lo que limita en cierta medida su transferencia, pues requieren de una adecuación biofísica y social local (cfr. Jarret, 1982, en Zuloaga y Pérez, 1996: 35). 
limita la posibilidad de seleccionar nueva semilla para el siguiente ciclo agrícola, y aunque el grano es grande, su sabor no se compara con el del maíz criollo (negro, rosado y blanco). ${ }^{7}$

En el Ejido Portes Gil, ubicado en el valle de Toluca, la decisión de los productores maiceros para mantener el cultivo de maíz está ligada al valor que las familias campesinas le atribuyen a la seguridad de disfrutar de ese bien. En ese sentido, la certeza se traduce tanto en el hecho de contar con la cantidad suficiente de maíz, como en el de producir un alimento de calidad que satisfaga sus preferencias; por ello se invierte dinero, trabajo y tiempo para mantener el cultivo (Cortés y Díaz, 2005: 179).

En cuanto a los fertilizantes químicos y orgánicos, la información del ciclo agrícola 2001-2002 precisa el uso de esos insumos en $12 \%$ de la superficie sembrada de la región del Alto Lerma (INEGI, 2004). En más de 50\% de las parcelas seleccionadas se ha incorporado el uso de mejoradores del suelo, con las más altas tasas de adopción entre 1961 y $1990^{8}$ (figura IX).

La Sedagro del Estado de México desempeña un papel fundamental en el proceso de transferencia de la tecnología agrícola, pues se constituye en el ente mediador entre los programas federales, las comercializadoras transnacionales y los productores maiceros; su papel está reforzando selectivamente la expansión del empleo de las nuevas semillas y los fertilizantes. ${ }^{9}$

${ }^{7}$ Los factores que limitan la adaptación geográfica de los maíces híbridos son los cambios de temperatura y humedad, y una serie de patógenos. La segunda generación de un híbrido tiene rendimientos inferiores; por ello, al agricultor no le conviene guardar la semilla, sino que debe comprar nueva semilla híbrida en cada ciclo agrícola (Pérez y Benítez, 1996: 123).

${ }^{8}$ En los años cuarenta se creó la infraestructura para la transferencia de los adelantos tecnológicos de fuerte componente estatal. Ese modelo de innovación introducido por el Instituto de Investigaciones Agrícolas se consolidó en los años sesenta; en ese entonces, la tecnología generada por el sector público se consideró un bien público, de libre acceso y no apropiable. Al inicio de los años ochenta, se puso en práctica la política de cambio estructural para insertar la economía en los mercados internacionales. El plan de ajuste dejó sin financiamiento a las actividades para el desarrollo agrícola nacional y aparecieron nuevos actores en la industria semillera, entre ellos las empresas transnacionales como las únicas capaces de generar nuevas variedades mejoradas; en contraste, en el otro extremo se ubicó el sector marginal de tecnología tradicional, el cual ha conservado, mejorado y protegido el germoplasma nativo en por lo menos 30,000 nichos ecológicos en todo el país (Pérez y Benítez, 1996: 122).

${ }^{9}$ En esa interacción es pertinente mencionar la noción de redes sociotécnicas propuesta por Antonio Arellano (Arellano y Ortega, 2003: 263), entendida como un complejo que reúne aspectos tan disímbolos como los materiales naturales, simbólicos y sociales en un solo haz en el que destacan no sólo las instituciones generadoras y mediadoras del proceso de transferencia de tecnología, sino que también desempeñan un papel preponderante los espacios sociales de reconocimiento y consumo, así como la interacción entre los actores sociales durante el proceso de aprendizaje. 
Figura IX

Región del Alto Lerma, México.

Periodos de adopción de fertilizantes químicos en las parcelas muestreadas (\% del total)

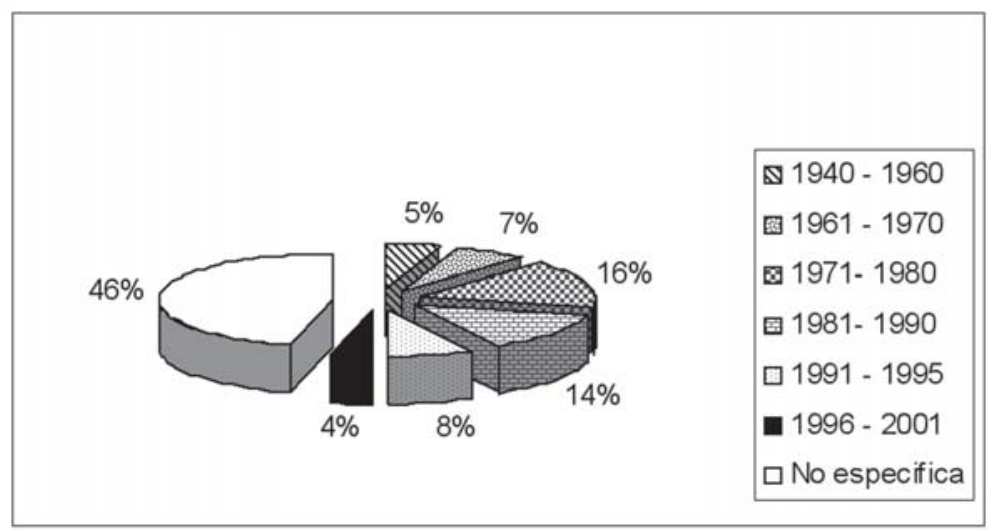

Fuente: Elaboración propia, 2001-2002.

\subsection{Empleo de mano de obra}

En la región del Alto Lerma predomina la mano de obra no remunerada en más de $85 \%$ de las unidades de producción ejidal, la cual es fundamentalmente de tipo familiar; por su parte, la mano de obra remunerada participa solamente en $10 \%$ de las unidades ejidales muestreadas, destacando la mano de obra eventual.

El tiempo de ocupación de mano de obra en la parcela se estima en un mínimo de 60 días y un máximo 250 días. El cultivo del maíz absorbe trabajo en la preparación de la tierra y en las labores de siembra y primera escarda, así como en la cosecha; pero en el periodo intermedio de varios meses, el consumo de trabajo es escaso.

En el caso de las parcelas muestreadas, más de $60 \%$ de los entrevistados contrató peones y pagó jornales; 35.5\% de los informantes pagó menos de un salario mínimo a cada peón contratado (figura $\mathrm{x}$ ). Lo anterior caracteriza un movimiento de mano de obra eventual en parcelas pequeñas y de temporal, en las que se paga sólo la tercera parte del costo de un jornal. ${ }^{10}$ En esos

${ }^{10}$ Las explotaciones típicamente familiares presentan situaciones muy variadas respecto al nivel de ingresos, lo cual depende del mayor o del menor grado de articulación con los mercados de productos y de trabajo. Considerando que la productividad del sector agropecuario en su conjunto es de tres a cuatro veces inferior a la de los sectores terciario y secundario, se deduce que los ingresos campesinos se situarían entre seis y siete veces por debajo de aquellos correspondientes a los sectores urbanos (De Grandi, 1996: 26). 
Figura $\mathrm{X}$

Región del Alto Lerma, México.

Montos de remuneración diaria a los peones contratados en las parcelas muestreadas (\%)

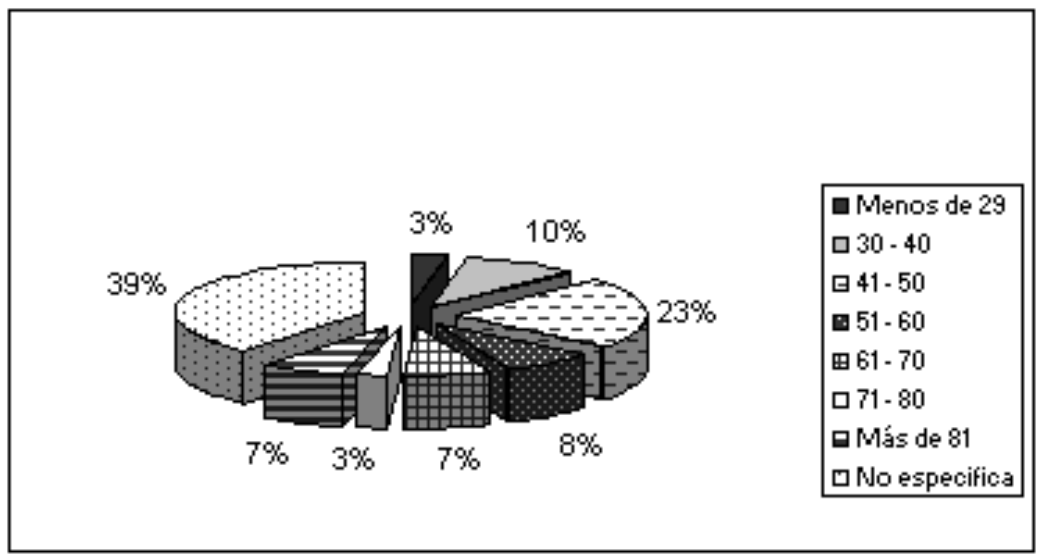

Fuente: Elaboración propia, 2001-2002.

casos, el ejidatario trabaja fuera de la parcela al servicio de otros ejidatarios o propietarios, en actividades artesanales, en el comercio, en la industria y en servicios diversos.

La organización individual y familiar de la producción agrícola plantea, por una parte, una economía agrícola de subsistencia, y, por la otra, significa la conservación de la práctica agrícola como un patrimonio familiar necesario y fundamental. En esa relación siempre estará presente el riesgo de la agudización del deterioro y de la pérdida de la relación directa con la tierra.

\subsection{Destino de la producción y precios}

Los resultados del muestreo de campo confirman que el destino principal de la producción es el autoconsumo (55\% de las parcelas), seguido por la relación venta-consumo (39\%) y la escasa participación de la venta del maíz como destino final (3\% de las parcelas).

Poco más de $60 \%$ de los ejidatarios entrevistados tiene satisfechas sus necesidades de consumo de maíz. No obstante, el sector ejidal que compra maíz, así como el que lo comercializa por necesidad, reflejan una economía familiar deficitaria. La deficiencia se aprecia al considerar el consumo diario y el costo del maíz. Por ejemplo, la familia ejidal promedio está compuesta por 
Figura XI

Región del Alto Lerma, México.

Otros cultivos (\%)

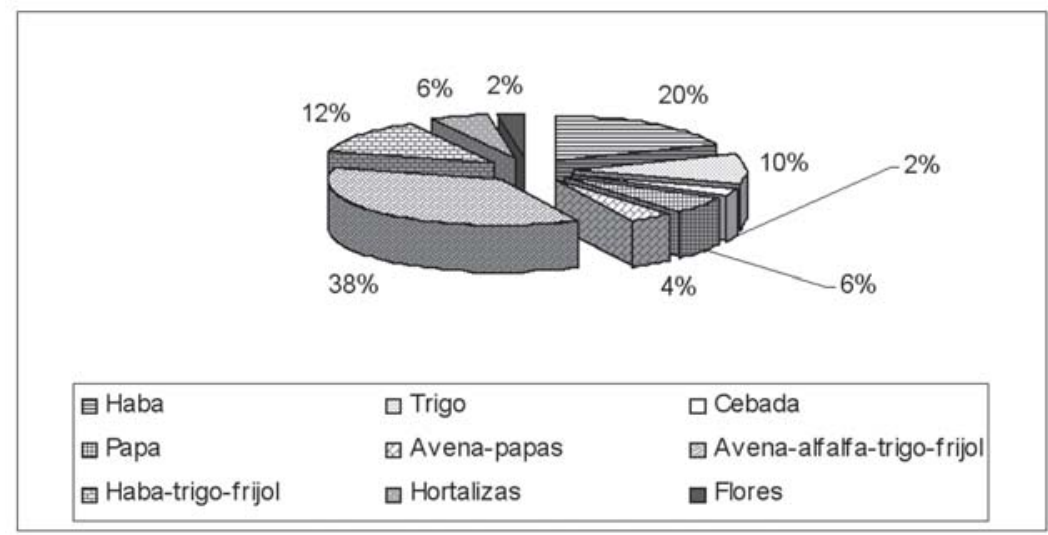

Fuente: Elaboración propia, 2001-2002.

siete personas, las cuales tienen un consumo diario de cinco kilogramos de maíz; es decir que consumen poco menos de dos toneladas de maíz anualmente. Tomando como base el precio del kilogramo de maíz en el ciclo agrícola 2001-2002 (3.0-3.50 pesos), una familia invirtió $\$ 17.50$ al día o $\$ 6,300$ pesos al año para la compra del maíz que consume, por lo que al no contar con ingresos suficientes por la venta de la cosecha, es frecuente que la fuerza laboral campesina busque otras alternativas para incrementar sus ingresos.

Los ejidatarios que venden maíz, lo comercializan directamente en el mercado local o lo venden a los intermediarios. La participación de la venta del maíz en el mercado regional es marginal, y muy pocos campesinos $(0.44 \%)$ venden su producción a los mayoristas. Algunos ejidatarios de la región de estudio han logrado colocar importantes volúmenes de maíz cacahuazintle en el mercado nacional. Los obstáculos fundamentales a que se enfrenta la producción de maíz de la región para tener acceso al mercado, son la importación del producto y los bajos precios de venta.

\section{Sistema de producción de otros cultivos}

Una parte importante (36.9\%) de los ejidatarios entrevistados en las parcelas muestreadas de la región del Alto Lerma diversifica su producción hacia otros cultivos. Destacan los de haba, trigo, cebada y papa (figura XI). La superficie sembrada de esos cultivos 
representó 24.81\% de la superficie sembrada de maíz (863.09ha), y sólo $17.92 \%$ de dicha superficie contaba con riego.

A pesar de que la producción de esos cultivos es costosa, coyunturalmente ha activado algunas economías locales; sin embargo, los bajos precios en el mercado, y en algunos casos la importación del producto, han derivado en el mediano plazo en el estancamiento de esas economías, tal como ocurre en los ejidos de Las Mesas y San Juan de las Huertas.

En los ejidos, por medio del apoyo de la Sedagro se ha difundido el establecimiento de invernaderos o huertos familiares en los que se cultiva cilantro, lechuga, betabel y acelga, pero su impacto comercial ha sido muy escaso y se destinan básicamente al consumo familiar. La producción de flores, champiñones y hongos seta se está convirtiendo en una alternativa de producción económicamente viable en la región, aunque los insumos agrícolas necesarios para esos cultivos son importados y comercializados por concesionarios locales y regionales.

En relación con el destino de la producción de los cultivos distintos al maíz, se identifica un sector ejidal comercial y semicomercial en productos como el trigo, las hortalizas, la papa, las flores y la avena forrajera, en tanto que los cultivos asociados con éstos se utilizan para el autoconsumo: $13.58 \%$ de los entrevistados en las parcelas muestreadas comercializa su producción en los mercados local y regional, y $63.58 \%$ destina una parte al comercio y otra al autoconsumo. La venta se realiza en dos modalidades: productor-intermediario y productor-mayorista, tanto en la Central de Abasto de Toluca como en la Central de Abasto de la Ciudad de México. Cuando el ejidatario lleva su producción a la Central de Abasto de Toluca, el trato es directo con los minoristas del área general y con los responsables de las bodegas, mientras que en la Central de Abasto de la Ciudad de México se enfrenta a los intermediarios. Los ejidatarios que cuentan con transporte propio tienen un mayor control sobre el proceso de comercialización de sus productos agrícolas y el precio de venta de los mismos, mientras que los ejidatarios que no poseen transporte lo rentan, y ello incrementa el costo final de sus productos.

\section{Sistema de producción pecuaria}

Más de la mitad (61.48\%) de los informantes cuenta con cabezas de ganado. En el hato de especies mayores destacan las mulas y los burros, que son utilizados para el transporte y el trabajo 
agrícola. En el conjunto ganadero regional predominan las aves (37.17\% del total de la población ganadera); en esa línea de producción, la Sedagro promueve pequeños proyectos de inversión para la crianza de aves para carne o postura; el apoyo es de cinco mil pesos y no es recuperable, ya que su finalidad es apoyar la alimentación familiar.

Solamente $6.66 \%$ de los ejidatarios tienen su ganado estabulado. Éste se asocia con sistemas intensivos de producción y con el cultivo de alfalfa, y su destino es la producción de carne y leche.

La ganadería permite el ahorro económico de las familias y es una actividad complementaria a la agricultura; en su carácter comercial, es promotora de la diversificación de cultivos, pues demanda la producción de forrajes y el fortalecimiento de la relación entre la agricultura y la engorda de ganado bovino para carne.

\section{Evidencias de la transformación social y territorial}

El significado que adquieren las evidencias de transformación en el sistema agrario ejidal de la región del Alto Lerma expresa la reivindicación y la readecuación de procesos que no son nuevos y que poseen una continuidad a lo largo de varias décadas. Sin embargo, las formas y ritmos de los cambios se relacionan directamente con el contacto físico y funcional del medio rural con el ámbito urbano; así, las continuidades son concomitantes al cambio de ocupación de la mano de obra ejidal, a la compra-venta de tierras y al cambio de uso del suelo. Las rupturas se identifican en el plano de la organización social y las formas de vida, así como en los sistemas de cultivo.

\subsection{Diversificación ocupacional de la mano de obra}

En la estructura demográfica destaca que $80 \%$ de los ejidatarios son hombres y $20 \%$ mujeres (INEGI, 2003). Los resultados de la encuesta esbozan una tendencia hacia el envejecimiento de la población ejidal en general y de los ejidatarios en particular, con una incipiente renovación. En la estructura por edad destacan el grupo de ejidatarios de 60 a 65 años y de más de 65 años (38.25\%), y el grupo de 50 a 59 años (25.73\%). Es decir que poco más de $60 \%$ de los ejidatarios entrevistados presentó una edad superior a los 50 años, mientras que $80 \%$ de las mujeres ejidatarias tiene una edad superior a los 40 años (cuadro 3). 


\section{Cuadro 3}

Estructura de edad y sexo de los ejidatarios

\begin{tabular}{lccrr}
\hline Rangos de edad & Hombres & Mujeres & Total & $\%$ \\
\hline $20-24$ & 4 & 4 & 8 & 2 \\
$25-29$ & 13 & 4 & 17 & 4 \\
$30-34$ & 19 & 1 & 20 & 5 \\
$35-39$ & 25 & 7 & 32 & 7 \\
$40-44$ & 38 & 9 & 47 & 11 \\
$45-49$ & 28 & 6 & 34 & 8 \\
$50-54$ & 63 & 7 & 70 & 16 \\
$55-59$ & 37 & 6 & 43 & 10 \\
$60-64$ & 61 & 7 & 68 & 15 \\
$65+$ & 80 & 20 & 100 & 23 \\
Total & 375 & 64 & 439 & 100 \\
\hline
\end{tabular}

Fuente: Elaboración propia, 2001-2002.

Alejandra Valenzuela (Valenzuela y Robles, 1996: 36 y 49) plantea que las mujeres ejidatarias, al superar, en la mayoría de los casos, la edad promedio de 50 años, se encuentran en la fase final de su actividad productiva, y por ello no trabajan directamente su parcela. Aunque las mujeres acceden a la tierra como viudas de los ejidatarios, lo que ocurre normalmente en una edad avanzada, se perfilan como sujetos de derechos agrarios y organizadoras de las actividades productivas y tienen un importante papel en la conservación de la transmisión de la tierra entre padres e hijos.

En cuanto al comportamiento demográfico de la población ejidal en general, la preponderancia del segmento de población de entre 15 y 29 años indica el incremento de la demanda no sólo de educación, sino también de empleo. Al respecto, poco menos de $50 \%$ de la población ejidal entrevistada cuenta con secundaria, preparatoria, educación técnica, normal o profesional; y en la medida en que la parcela no absorbe la mano de obra, los jóvenes optan por buscar el futuro en trabajos no agrícolas, al mismo tiempo que se producen cambios en la composición social y laboral del sistema social ejidal.

La estructura de la ocupación en la población ejidal muestreada refleja la importancia que tiene en la región del Alto Lerma el trabajo agropecuario como la actividad principal (49\% de los informantes) o bien como actividad complementaria (21\%); destacan como actividades específicas el comercio, la construcción (albañilería) y el servicio doméstico. 
En el ámbito regional se presenta lo que pudiese llamarse una especialización laboral. Por ejemplo, en el municipio de Almoloya de Juárez las entrevistas reportan el predominio de la mano de obra femenina dedicada al servicio doméstico, y en el municipio de San Felipe del Progreso, la mano de obra masculina dedicada a la albañilería.

Los jefes de la familia ejidal, conscientes de que el maíz que se produce no proporciona beneficios económicos a la familia ni tampoco es suficiente para su subsistencia, permiten la salida de los hijos (en particular de las mujeres) ${ }^{11}$ para que trabajen en otras actividades ajenas al campo y apoyen con ello el sostenimiento familiar. En la incorporación de las mujeres al trabajo urbano, se diluye la diferencia de género. Al mismo tiempo, esa incorporación se constituye, por una parte, en una estrategia que se asume en las familias ejidales, y por la otra, en un retraso de la vida en pareja de esas mujeres, aspecto que repercute en los ciclos de reproducción y en el mediano plazo afecta el tamaño de familia rural. ${ }^{12}$ El mercado de trabajo urbano es uno de los mecanismos principales de la articulación de la población ejidal al ámbito citadino, y los destinos principales son las zonas metropolitanas de Toluca y la Ciudad de México. Los movimientos de mano de obra a otras entidades y hacia el extranjero son escasos.

En el proceso de incorporación al mercado de trabajo urbano, predomina la frecuencia de regreso diario y semanal. Aun cuando la población que se desplaza invierte como promedio más de dos horas en su recorrido, éste es asumido como parte de su

${ }^{11}$ La diversificación ocupacional ha supuesto la modificación de la división sexual y generacional del trabajo dentro de las unidades domésticas. Así, además de la incorporación del trabajo infantil, destaca la participación creciente de las mujeres rurales en actividades remuneradas, tanto en el sector agroindustrial y la maquila como en el sector de los servicios. De este modo, las necesidades internas de la familia se combinan con una creciente demanda de fuerza de trabajo femenina en algunos sectores económicos en expansión, como la agroindustria de exportación y la agricultura comercial, los parques industriales ubicados en el medio rural o la industria maquiladora a domicilio y en talleres (Bonfil, 1996: 73).

${ }^{12}$ A partir de la conceptuación de Alexander Chayanov (1974) de la unidad doméstica campesina, diversos autores se dedicaron a analizar las estrategias de reproducción de grupos domésticos en contextos urbanos y rurales. El concepto de estrategias de supervivencia explica cómo se determina la estructura de la familia en el contexto de la reproducción social; se refiere a aquellas estrategias que hacen posible la reproducción de la fuerza de trabajo en el seno de la familia, y en ellas se incluyen tanto la adopción de patrones migratorios y de una división del trabajo por edad y sexo, como la adecuación del comportamiento asociado con la nupcialidad y con la constitución de la descendencia. Ello significa que el comportamiento demografico de los individuos sólo es inteligible a la luz de la estrategia de supervivencia de la familia a la que pertenecen ( $c f r$. Torrado, 1978: 345, en Acosta, 2003: 20). 
vida cotidiana, ya que el ingreso económico producto del trabajo urbano, por mínimo que sea, representa una entrada importante desde el punto de vista de su destino, en el que destaca su inversión en alimentos y en apoyar la actividad agrícola.

\subsection{Rupturas culturales}

Las rupturas culturales experimentadas en la región del Alto Lerma se evidencian en distintos aspectos. Uno de los más frecuentes es la negación de la lengua originaria como resultado del proceso de asimilación del sector indígena ejidal a la población en su conjunto, como lo refleja el hecho de que $14 \%$ de la población ejidal contabilizada en la muestra habla las lenguas mazahua y otomí.

Por otra parte, aun cuando predomina la religión católica en el 96\% de las unidades muestreadas, se puede afirmar que la religión ${ }^{13}$ evangélica toma cada vez más fuerza en el ámbito local, sobre todo en el plano organizativo y cooperativo. La adopción de "religiones nuevas"14 está provocando la ruptura en las formas de organización social y familiar fundadas en las costumbres tradicionales. ${ }^{15}$

En cuanto a las formas de organización social, destacan la mayordomía y la cooperativa. La mayordomía se puede considerar como un relicto del sistema de cargos implantado en el valle de Toluca-caciquismo de carácter social y político.

En el ejido de San Miguel Almoloyan presenciamos el cambio del sistema de cargos en la fiesta de San Isidro (octubre a agosto). Los mayordomos salientes invitaban directamente a los jóvenes a participar, y éstos mostraban resistencia por los gastos que ello implicaba.

${ }^{13}$ La religión, al igual que el Estado, mediante sus directrices, normas y procedimientos configura nuestras identidades y acciones de manera profunda e irrevocable (Roseberry, 1998: 96).

${ }^{14}$ Las religiones protestantes, por medio de sus discursos y acciones, construyen valores y realidades sociales de transformación. El individuo que acepta un cambio de religión determinada es un sujeto social que busca formas alternas para desarrollar un estilo de vida; así, la conversión religiosa se entiende como un proceso de cambio de identidad personal, es desear construir un proyecto de vida distinto, por lo que es equiparable a una construcción social (Fabré, 2001: 278, 286 y 307).

${ }^{15}$ La secta denominada "La Luz del Mundo", cuya presencia se ha identificado en la región en estudio, induce a los feligreses a cooperar con 50 pesos mensuales para ayudar económicamente a los nuevos integrantes (cadenas de apoyo). En el caso de los ejidatarios, su conversión a ese culto les ha conducido a separarse del conjunto social del que forman parte, pues ya no participan en las fiestas religiosas ni cívicas, aunque han mejorado su situación económica. 
Actualmente, la mayordomía es la forma de organización social más cercana a la tradición; sin embargo, se acerca cada vez más a una cooperativa en la que participan varias personas. ${ }^{16} \mathrm{El}$ número de mayordomos varía de un ejido a otro; por ejemplo, en Tlalchichipan, Almoloya de Juárez, son 10 mayordomos, y en San Cristóbal Huchochitlán, Toluca, son 80. En los ejidos de Temoaya, Zolotepec y Mimiapan se puede apreciar la variación de esa costumbre: en el primer ejido ya no se organizan fiestas patronales; en el segundo se conserva el sistema de cargos y la mayordomía, y en el tercero existe el sistema de fiestas, pero ya no se practica la mayordomía.

Con relación al compadrazgo y su papel en el desarrollo del trabajo agrícola y las actividades familiares, ${ }^{17}$ 91\% de los entrevistados confirmó tener compadres, $6 \%$ no los tenía y $3 \%$ no lo especificó.

La mayoría de los entrevistados sotuvo que los "compadritos" no les apoyaban en nada, y 9 y $15 \%$ de ellos mencionó que les ayudaban en el trabajo de la parcela y en el cuidado de los ahijados, respectivamente. La mayoría de los ejidatarios no vio ninguna ventaja en esa relación social, lo cual muestra la transformación de una costumbre que por tradición era socialmente integradora. ${ }^{18}$

Las festividades religiosas ${ }^{19}$ son un componente importante de las relaciones sociales y productivas entre los ejidatarios; las

${ }^{16}$ Las fiestas y otros rituales públicos resaltan aspectos de los procesos de afirmación, confrontación y reconfiguración de valores. Esto es especialmente cierto durante los periodos de mayor cambio social, cuando los valores y las actitudes se polarizan o se hacen más ambiguos (Long, 1998: 63).

${ }^{17}$ Los otomíes y mazahuas designaban con el nombre de "compadres" a los jefes de familia que están ligados por la reciprocidad obligatoria de los regalos en las fiestas. Ningún lazo de parentesco tiene, a los ojos de los indios, una significación tan profunda como las relaciones de ayuda en las fiestas familiares. Esas cadenas de servicios recíprocos y obligatorios ligan la vida de un hombre durante toda su existencia, y son ellas, en gran parte, las que aseguran la cohesión de las pequeñas comunidades (Soustelle, 1993: 608).

${ }^{18}$ Tradicionalmente, en la región en estudio las funciones del compadrazgo cubrían la gama completa de la organización social, religiosa, económica y política, además de desempeñar ciertas funciones símbólicas en algunos ritos de acción de gracias. El compadrazgo se constituía en un modelo de alianza comunitaria que permitía extender los lazos de cooperación, intercambio y ayuda más allá del parentesco, al mismo tiempo que desempeñaba el papel de estructurante del control social, pues tradicionalmente un compadre de alta estima cubría las expectativas económicas y sociales de una familia (Sugiura et al., 1997: 46).

${ }^{19}$ Las fiestas religiosas son una herencia del cristianismo colonial y un rasgo carácterístico de la cultura mesoamericana; su realización se relaciona con el ciclo de cultivo del maíz de temporal y se vincula con el calendario. El día 2 de febrero se bendice la semilla de maíz y otras plantas que habrán de sembrarse en el ciclo agrícola, el cual se considera desde su siembra (marzo-mayo) hasta su cosecha (octubre-noviembre) (Albores, 2004: 5 y 6). 
fechas de su realización se relacionan con los ciclos del cultivo de maíz, en particular el ciclo primavera-verano. Las fiestas se inician desde el mes de marzo con la siembra, y duran hasta noviembre con la cosecha.

Por otra parte, la pérdida de las costumbres relacionadas con el cultivo de la tierra evidencia la ruptura de la cadena económica-religiosa basada en las fiestas, en el compadrazgo, en la reciprocidad y en la producción del maíz, así como en las maneras de pensar de los ejidatarios de la región.

No obstante que una buena parte de los entrevistados señala que siembra el maíz por costumbre, se entiende que el conocimiento y la práctica agrícola adquirida de generación en generación trascienden racionalmente la necesidad de alimentación y reproducción social de la población ejidal.

En cuanto a las costumbres asociadas con el cultivo del maíz, se identifica el uso de semilla criolla, la práctica de la segunda escarda, el empleo de la yunta para las labores, y el uso del abono. Ello reafirma la concepción del ejidatario en cuanto al carácter tradicional e individual del trabajo agrícola.

Entre las costumbres que tienden a desaparecer, y en algún caso están extintas, destacan la ayuda como práctica de trabajo colectivo, la siembra de avena, trigo o cebada; la siembra tapa-pie, la bendición de la semilla y la cosecha, el apoyo de los hijos en las labores del campo, la palma de lluvia y la bendición de los animales.

Por otra parte, la transformación del espacio habitado no sólo involucra las características arquitectónicas de la vivienda, ${ }^{20}$ sino también los cambios que se inducen por la interacción social de sus habitantes mediante la incorporación de bienes producto del ingreso aportado por el trabajo migratorio urbano.

En el caso estudiado destacan principalmente los materiales industrializados en la edificación de la vivienda: el tabique en las paredes, la loza en los techos y el cemento en los pisos, mientras que los materiales tradicionales como el adobe y la teja se utilizan cada vez menos. El aspecto suburbano de la vivienda ejidal identifica una intencionalidad que tiene que ver no sólo con el cambio del espacio habitado, sino también con la aspiración a una forma de vida diferente a la rural.

La posesión de ciertos bienes, reflejo de la vida urbana, expresa otra de las maneras como los ejidatarios se articulan cada

${ }^{20} \mathrm{La}$ comunidad es una unidad territorial con espacios delimitados -barrios, parajes, la casa, el patio o solar, el corral o jardín-, todos ellos componentes de la vivienda rural y jerarquizados según su función económica y social (Ávila, 1996: 70). 
Figura XII

Región del Alto Lerma, México.

Preferencias en la programación televisiva (\%)

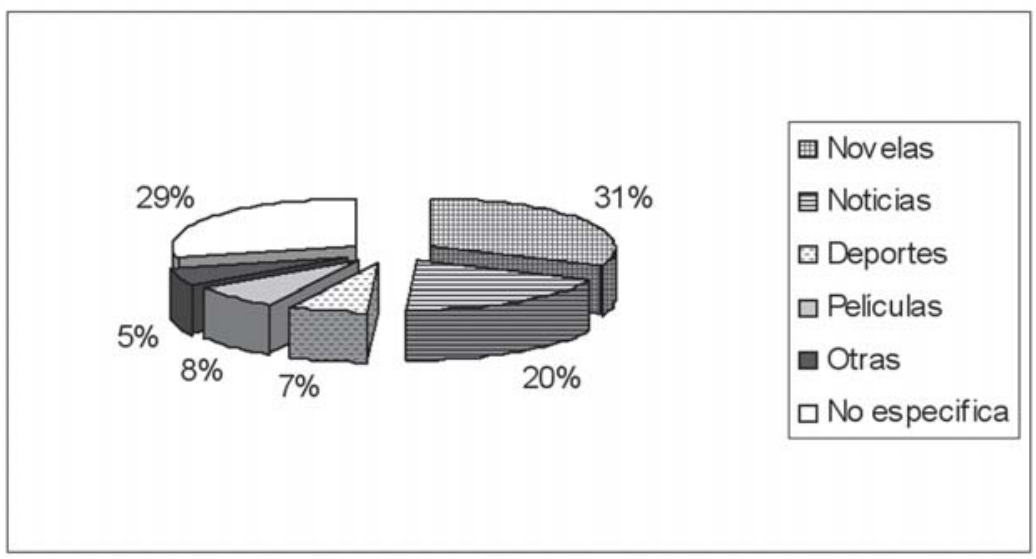

Fuente: Elaboración propia, 2001-2002.

vez más al mundo de la modernidad. La presencia del televisor en $78 \%$ de las unidades muestreadas y las preferencias en cuanto a tipo de programas ${ }^{21}$ indican que la información verídica o deformada recibida a través de ese medio es procesada y adoptada de manera consciente e inconsciente, lo cual induce cambios en el comportamiento social y familiar ejidal ${ }^{22}$ (figura XII).

La existencia de la estufa de gas en $74 \%$ de las casas es el resultado de un proceso reciente de incorporación; la adquisición de ese bien presenta su mayor auge en el quinquenio de 1986 a $1990(15.26 \%)$ y de 1991 a 1995 (14.35\%), de forma global desde 1981 al 2001 (55.56\%). La sustitución del fogón de leña típico de la vivienda rural de la zona, así como la incorporación de otros bienes, expresan cambios en los procesos de intercambio, convivencia y preferencias de las personas que la habitan; esos aspectos están repercutiendo en la organización familiar.

${ }^{21}$ Los procesos educativos no formales que se producen por la intervención de los medios de comunicación de masas, radio y televisión, en el núcleo familiar, moldean las actitudes y el consumo de los sujetos sociales (De Ibarrola, 1988: 45).

${ }^{22}$ Las imágenes que se transmiten por la televisión ocupan un lugar central en las transformaciones de los repertorios culturales en todo el mundo. Las formas como se perciben y procesan los mensajes varían considerablemente, puesto que las interpretaciones y el conocimiento local tienen un efecto de filtro sobre la comunicación generada externamente (Long, 1998: 69). 
Figura XIII

Región del Alto Lerma, México.

Opiniones de los informantes sobre compra-venta de terrenos

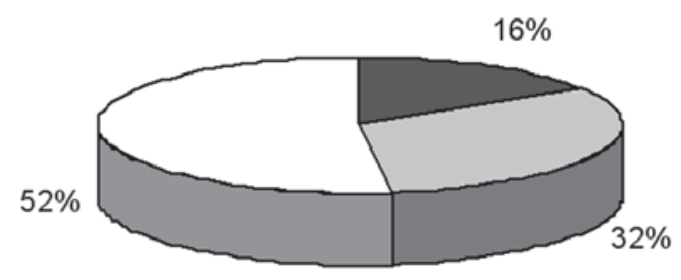

Mucho

Poco

Nada

Fuente: Elaboración propia, 2001-2002.

\subsection{Mercado de tierras}

No obstante que los ejidatarios de la región del Alto Lerma reconocen diferentes calidades de tierra, poco más de $90 \%$ de los entrevistados considera que es muy importante conservarla ${ }^{23}$ (figuras XIII y XIV). En poco más de $90 \%$ de los casos muestreados la tierra es propia, en $3 \%$ es rentada y tomada a medias, y en 5 y $1 \%$ es comprada y no se especifica, respectivamente.

Las modalidades de compra-venta, renta y aparcería representan el circuito comercial de la tierra, en cuyo caso se recibe dinero. Las formas de intercambio cuya base son las relaciones sociales comunitarias son la mediería y el préstamo.

En los terrenos comprados predominan los usos agrícola y habitacional. Trátese de transacciones mercantiles o no, los actores sociales que participan en los intercambios son principalmente ejidatarios-ejidatarios, ejidatarios-particulares, y ejidatarios-posesionarios. Actualmente ya se percibe en las transacciones comerciales de tierras la participación de intermediarios y extranjeros.

${ }^{23}$ Los argumentos del mercado en favor de la privatización de la tierra ejidal en México han encontrado resistencia debido, en gran parte, a la existencia de solidaridades campesinas, las cuales buscan promover un sentido de comunidad e igualdad. Es relativamente fácil decretar la privatización de los recursos comunitarios, pero otra cosa es convencer a los campesinos de hacer a un lado sus intereses y valores comunitarios o ejidales en favor de actitudes acordes al neoliberalismo (Long, 1998: 60). 
Figura XIV

Región del Alto Lerma, México.

Opiniones de los informantes sobre

la renta de terrenos

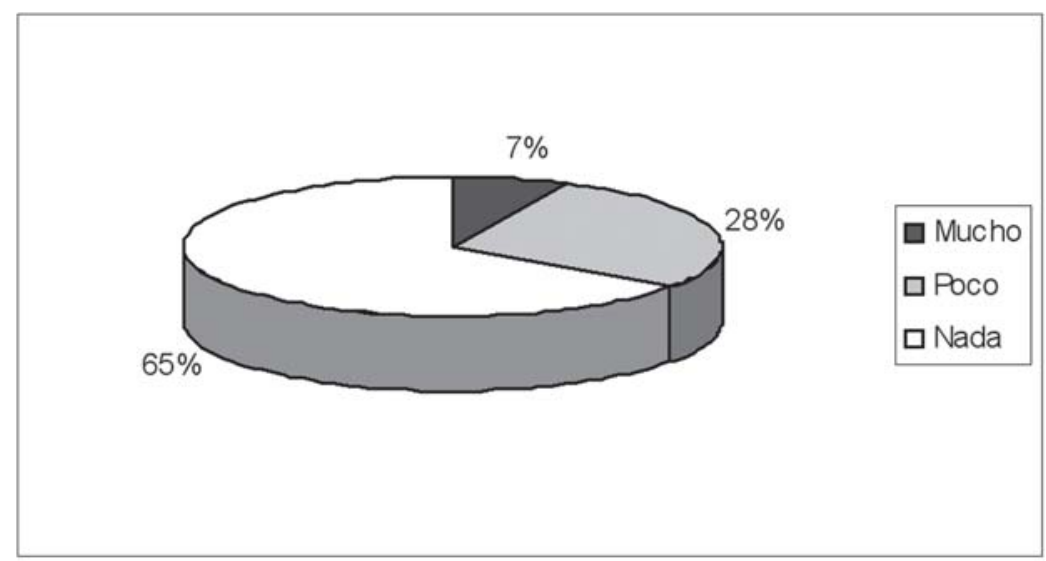

Fuente: Elaboración propia, 2001-2002.

La mercantilización de la tierra es aguda en los ejidos cercanos a los centros de población importantes y a las vías de comunicación, y en menor medida en las tierras más agrestes de la porción norte de la región.

La inmigración es otro factor que contribuye al proceso de trasformación de los ejidos. La magnitud del fenómeno es variable; los ejidatarios que habitan en el sur y centro de la región coinciden en afirmar que los terrenos ocupados por los inmigrantes eran originalmente de cultivo.

En cuanto al origen geográfico de los inmigrantes, destacan varios municipios de la propia región, en particular el municipio de Toluca, y como otros orígenes, el Distrito Federal y los estados de Michoacán y Oaxaca. Con base en esto se puede decir que el proceso de repoblamiento de las zonas ejidales se debe a la inmigración intra e intermunicipal vinculada con la expansión de la Zona Metropolitana de Toluca, mientras que la inmigración extrarregional es incipiente pero se presenta como una forma de articulación específica.

El efecto disolvente más palpable es la incorporación de la superficie ejidal al proceso de urbanización. Uno de los mecanismos para incorporar tierra ejidal a la urbanización han sido las expropiaciones. Es el caso de los ejidos de San Felipe Tlalmimilolpan y el de Santa María de las Rosas Yancuitlalpan, que se han 
convertido en colonias de la Zona Metropolitana de la Ciudad de Toluca.

Cabe decir que los programas de certificación y regularización de la propiedad de la tierra no han tenido el éxito deseado, pues los propios ejidatarios fraccionan sus terrenos para venderlos como lotes urbanos, en virtud de que cuando esos terrenos les son expropiados no les conviene recibir un pago por hectárea.

\subsection{Incorporación de tecnología en los sistemas de cultivo}

Antonio Arellano (1999: 246) documenta que en 1988, sólo 1.76\% de la superficie cultivada en el Estado de México fue sembrada con variedades de maíz mejorado e híbrido, y que la mayor parte de los agricultores de los valles altos rechazaban formar parte de la red sociotécnica del maíz. Los resultados obtenidos en esta investigación exponen que poco más de $85 \%$ de los ejidatarios entrevistados utilizan la semilla criolla y muy pocos la mejorada y la híbrida. Se documenta que en el poblado de San Pedro de la Concepción, ubicado en el valle Toluca, la gran mayoría de los agricultores continúan sembrando semillas autóctonas; los híbridos y las variedades mejoradas no son opciones técnicas reales, en tanto que no crecen adecuadamente dadas las condiciones geográficas de la zona (Arellano y Jordán, 2001: 255).

El empleo de las nuevas semillas es la concreción incipiente de la inducción de un nuevo cambio tecnológico en el cultivo de maíz que ha sido ampliamente promovido por los gobiernos federal y estatal, así como por la Unión de Productores de Maíz del Estado de México y la Federación de Propietarios Rurales del Estado de México.

En cuanto el uso de fertilizantes químicos en el cultivo de maíz, la reconstrucción del proceso de adopción identifica que en un lapso de 20 años (1940-1960), los ejidatarios del Alto Lerma se asimilaron a una primera etapa de cambio tecnológico basada en ese tipo de insumos agrícolas. Al momento de la encuesta, más de $50 \%$ de los ejidatarios entrevistados de la región utilizaban fertilizantes químicos en la producción del maíz.

La producción de otros cultivos es imperceptible en la escala regional; sin embargo, en el ámbito local, 37\% de los informantes cultiva productos diferentes al maíz. Es precisamente en ese sector de la agricultura en el que se aprecia la instrumentación de una segunda etapa de cambio tecnológico, sobre todo en el cultivo de hortalizas, papa y flores. Esos cultivos requieren de 
tecnología especial en la que el uso de fertilizantes y semillas mejoradas e híbridas es frecuente.

\section{Consideraciones finales}

Los ejidatarios de la región del Alto Lerma son sujetos conscientes del deterioro de su forma de vida, lo cual les conduce a tomar decisiones que se concretan mediante diversas estrategias para asegurar su pervivencia (ocupación en actividades urbanas, empleo femenino, diversificación de cultivos y cambio tecnológico, venta de tierras, cambio de costumbres, defensa de los precios del maíz, uso del material genético criollo, etcétera). Esas estrategias son producto de racionalidades individuales, que desde el interior están promoviendo las tendencias de adaptación y de transformación del sistema agrario y de su entorno regional con el fin de evitar su desaparición.

La transformación de la forma de vida y de la organización social ejidal es resultado de los contactos físicos y funcionales con el ámbito urbano, y los principales vehículos de esa transformación son el mercado de trabajo urbano, el mercado de productos agrícolas, el transporte, la radio y la televisión.

En virtud de los procesos de urbanización e industrialización y del aumento irreversible de la población, el sistema agrario ejidal y las variadas economías agrarias del Alto Lerma presentan diferentes sensibilidades al cambio; se puede decir que las formas y ritmos de la transformación variarán en función de la cercanía, contigüidad y articulación funcional con las zonas urbanas e industriales.

En los ejidos cercanos a centros de población de importancia existe una mayor tendencia a las formas mercantiles de intercambio de tierras y, por ende, una elevada susceptibilidad a la conversión del uso del suelo agrícola por otros usos, mientras que en los ejidos eminentemente rurales se practica la renta de la tierra y la aparcería como formas de intercambio mercantil limitado, y el préstamo y la mediería como intercambio no mercantil, cuya base siguen siendo las relaciones solidarias entre los ejidatarios.

Los cambios espaciales de los ejidos periféricos a las zonas urbanas concuerdan también con las transformaciones operadas tanto en el volumen de población ejidal como en su estructura social y económica, los cuales se han visto envueltos en la dinámica funcional rural-urbana, y en el tránsito continuo y cada vez 
más intenso entre la vida agrícola del ejido y la vida urbana de las actividades secundarias y terciarias.

Los ejidatarios han sido sensibles a las innovaciones tecnológicas del modelo productivo inducido por el uso de fertilizantes químicos; no obstante, asumir el nuevo modelo agrícola con base en el empleo de semillas mejoradas e híbridas es un proceso lento, con sensibles limitaciones biofísicas, sociales y económicas.

Las diferentes respuestas de las economías ejidales locales identificadas definen una tendencia hacia la transformación social, económica y territorial de la región del Alto Lerma, con ritmos diferenciados en función de las limitaciones o potencialidades internas y externas, por lo que el momento del cambio definitivo no es perceptible en el corto plazo.

\section{Bibliografía}

Acosta, Félix (2003), “La familia en los estudios de población en América Latina: estado del conocimiento y necesidades de investigación", Papeles de Población, Centro de Investigación y Estudios Avanzados de la Población, Toluca, México, julio-septiembre, año 9 (37): 9-50.

Albores Zárate, Beatriz (2004), Las fiestas religiosas mexiquenses. Un esquema inicial, Documento de Trabajo, núm. 89, El Colegio Mexiquense, A.C., Zinacantepec, México.

Arellano Hernández, Antonio (1999), La producción social de objetos técnicos agrícolas. Antropología de la hibridación del maíz y de los agricultores de los Valles Altos de México, Coordinación General de Investigación y Estudios Avanzados, UAEM-Chimal Editores, Toluca, México.

y Carlos Arriaga Jordán (2001), “Why Improved Maize (Zea mays) Varieties are Utopia in Highlands of Central México”, Convergencia, Facultad de Ciencias Políticas y Administración Pública, UAEM, Toluca, México, mayo-agosto, año 8 (25): 255-276.

__ y Claudia Ortega Ponce (2003), "Las redes sociotécnicas en torno a la investigación tecnológica del maíz”, Convergencia, Facultad de Ciencias Políticas y Administración 
Pública, UaEm, Toluca, México, mayo-agosto, año/vol. 12 (38): 255-276.

Ávila, Agustín (1996), "Etnia y movimiento campesino en la Huasteca Hidalguense", en Fernando Rello (coord.), Las organizaciones de productores rurales en México, Facultad de Economía, unam, México, pp. 65-96.

Bonfil Sánchez, Paloma (1996), "Las familias rurales ante las transformaciones socioeconómicas recientes”, Estudios Agrarios, Procuraduría Agraria, México, octubre-diciembre, 5: 64-78.

Bueno Castellanos, Carmen (2000), Globalización, una cuestión antropológica, CIESAS-Grupo Editorial Miguel Ángel Porrúa, México.

Calva, José Luis (1996), "El sector agropecuario mexicano después del colapso financiero de 1994-1995”, en José Luis Soleiro, María del Carmen del Valle y Ernesto Moreno (coords.), Posibilidades para el desarrollo tecnológico del campo mexicano, tomo I, Instituto de Investigaciones Económicas-Programa Universitario de Alimentos-Centro para la Innovación Tecnológica, UnAM-Cambio XXI, Colección La estructura económica y social de México, México, pp. 15-26.

Centro de Estudios para el Desarrollo Rural Sustentable y la Soberanía Alimentaria (2005), Reporte: Elementos de Apoyo para la Iniciativa de Ley de Planeación Agropecuaria, http://www.sagarpa.gob.mx/cmdrs/CEDRSSA/DG/ IRP/002/05, 09 de enero de 2006.

Cofupro (Coordinadora Nacional de las Fundaciones Produce) (2005), Boletín \# 28, 10 de agosto, http://www.sifp.org. mx/file/boletin/boletin28.pdf, 13 de marzo de 2006.

Cortés Vázquez, Lorena y José Valdemar Díaz Hinojosa (2005), "La seguridad alimentaria y la producción de maíz en un entorno de mercado, Estudios Agrarios, Procuraduría Agraria, México, 29: 105-182. 
Chayanov, Alexander (1974), La organización de la unidad económica campesina, Ediciones Nueva Visión, Buenos Aires.

De Grandi, Juan Carlos (1996), El desarrollo de los sistemas de agricultura campesina en América Latina, un análisis de la influencia del contexto socioeconómico, Organización de las Naciones Unidas para la Agricultura y la Alimentación (FAO), Roma, Italia.

De la Garza Toledo, Enrique (1994), "Reestructuración espacial y reconversión industrial”, en Mario Bassols (coord.), Campo y ciudad en una era de transición: problemas, tendencia y desafíos, UAm-Iztapalapa, Casa Abierta al Tiempo, México, pp. 47-67.

De Ibarrola, María (1988), "Hacia una reconceptualización de las relaciones entre el mundo de la educación y el mundo del trabajo en América Latina", Revista Latinoamericana de Estudios Educativos, México, vol. XII (2): 963.

Fabré Platas, Danú A. (2001), “Conversión religiosa e imaginario social: el discurso como elemento de análisis", Convergencia, UAEM, Toluca, México, mayo-agosto, año 8 (25): 277-308.

GEM (Gobierno del Estado de México) (1982), Calculo de poligonales del Estado de México, Subdirección de Estudio y Consulta de Territorio Estatal (SECTE), Toluca, México (mimeo.).

(1997), Atlas Ecológico de la Cuenca Hidrográfica del Río Lerma, Tomo III, Ecosistemas productivos, Comisión Coordinadora para la Recuperación del Río Lerma, Toluca, México.

- (2000), Atlas Industrial de la Cuenca Hidrográfica del Río Lerma, Tomo v, Comisión para la Recuperación del Río Lerma, Toluca, México.

Hernández Navarro, Luis (1994), “¿Reforma o contrarreforma? Notas sobre el impacto de Reformas al 27 Constitucional”, en Emilio Romero (coord.), Apertura económica y perspectivas del sector agropecuario mexicano hacia el año 2000, IIE, UNAM, México, pp. 197-205. 
Hiernaux-Nicolás, Daniel (1994), "De frente a la modernización, hacia una nueva geografía de México", en Mario Bassols (coord.), Campo y ciudad en una era de transición: problemas, tendencia y desafíos, UAM-Iztapalapa, Casa Abierta al Tiempo, México, pp. 19-43.

INEGI (Instituto Nacional de Estadística, Geografía e Informática) (1991), Listado de Ejidos y Comunidades Agrarias, Documento de trabajo para los viI Censos Agropecuarios 1991, Dirección Regional Centro-Sur, INEGI, Toluca, México.

(1991), Resultados preliminares del cuestionario naranja, aplicado a comisarios ejidales en el VII Censo Agropecuario, Documento de trabajo, Dirección Regional Centro-Sur, INEGI, Toluca, México.

(1994), Resultados Definitivos. VII Censo Agrícola, Ganadero y Ejidal. Estado de México, INEGI, Aguascalientes, México.

(1997), Datos por ejido y comunidad agraria, INEGI, Aguascalientes, México.

(2000), Tabulados Básicos Nacionales y por Entidad Federativa, XII Censo General de Población y Vivienda 2000, INEGI, Aguascalientes, México.

(2003), Censo Ejidal 2001, Sistema de Consulta Electrónica, versión 0.1, INEGI, Aguascalientes, México.

(2004), Anuario Estadístico del Estado de México, inegi.gob.mx/inegi/default.asp, 28 de febrero de 2006.

Long, Norman (1998), “Cambio rural, neoliberalismo y mercantilización: el valor social desde una perspectiva centrada en el actor”, en Sergio Zendejas y Pieter de Vries (eds.), Las disputas por el México rural, volumen 1, actores y campos sociales, El Colegio de Michoacán, México, pp. 45-72.

OCDE (Organización para la Cooperación y el Desarrollo Económico) (1997), Políticas nacionales y comercio agrícola. Examen de las políticas agrícolas de México, OCDE, México. 
Orozco Hernández, María Estela (2003), Sistema Agrario Ejidal en el contexto de la globalización: el caso de la Cuenca Alta del Río Lerma, México, tesis de doctorado, Facultad de Filosofía y Letras, unam, México.

(2005), "Aportaciones teóricas para los estudios urbanos y regionales”, Ciencia Ergo Sum, UAEM, México, 12 (3): 110.

y María Teresa Sánchez-Salazar (2004), “Organización socioeconómica y territorial en la región del Alto Lerma, Estado de México”, Investigaciones Geográficas. Boletín del Instituto de Geografía, unam, México, 53: 163-184.

, Vicente Peña Manjarrez, Roberto Franco Plata y Noel Bonfilio Pineda Jaimes (2004), Atlas Agrario Ejidal del Estado de México, uaem, Toluca, México.

Palacios Rangel, María Isabel y Tomás Martínez Saldaña (2005), La maquila agrícola, un proceso social en el desarrollo rural, Congreso Internacional, Perspectivas del desarrollo rural regional, Gobierno de Michoacán-Lxx LegislaturaUniversidad Autónoma de Chapingo-Instituto Nacional de Investigaciones Forestales, Agrícolas y Pecuarias, Morelia, Michoacán, 24, 25 y 26 de octubre de 2005.

Pérez Jerónimo, Guillermo y Eduardo Benítez Paulín (1996), "Estructura actual de la industria semillera en México", en José Luis Soleiro, María del Carmen del Valle y Ernesto Moreno (coords.), Posibilidades para el desarrollo tecnológico en el campo mexicano, tomo II, Instituto de Investigaciones Económicas-Programa Universitario de Alimentos-Centro para la Innovación Tecnológica, UNAMCambio xxi, Colección La estructura económica y social de México, México, pp. 119-133.

Pérez Pascual, Alejandro (1994), "Participación campesina y legislación agraria”, en Emilio Romero Polanco et al. (coords.), Apertura económica y perspectivas del sector agropecuario mexicano hacia el año 2000, Instituto de Investigaciones Económicas, UnAM, México, pp. 217-226. 
Pradilla Cobos, Emilio (2002), “Campo y ciudad en el capitalismo actual", Ciudades, Red Nacional de Investigación Urbana, Puebla, México, abril-junio, 54: 3-8.

Roseberry, William (1998), "Cuestiones agrarias y campos sociales”, en Sergio Zendejas y Pieter de Vries (eds.), Las disputas por el México rural, volumen 1, actores y campos sociales, El Colegio de Michoacán, México, pp. 73-97.

Ruellan, Alain y Pierre Godard (1994), "Sociedades rurales y transformaciones agrarias", en Thierry Linch (comp.), Agriculturas y campesinados de América Latina: mutaciones y recomposiciones, Institut Français de Recherche Scientifique pour le Développement en Coopération Groupe de Recherche sur l'Amérique Latine-Fondo de Cultura Económica, México, pp. 251-254.

Sagar (Secretaría de Agricultura y Ganadería) (2001), Programas de apoyo al campo, http://www.sagar.gob.mx, 20 de enero de 2003.

Servicio de Información y Estadística Agroalimentaria y Pesquera (SIAP), Anuario Estadístico de la Producción Agrícola (Sagarpa), http://www.siap.sagarpa.gob.mx, 30 de enero de 2006.

Sierra Bravo, Restituto (1995), Técnicas de investigación social. Teoría y ejercicios, $10^{a}$ ed., Editorial Paraninfo, Madrid.

Soustelle, Jaques (1993), La familia otomí-pame, Gobierno del Estado de México-Uaem-Ateneo del Estado de MéxicoInstituto Mexiquense de Cultura, Toluca, México.

Sugiura, Yoko, Patricia Martel y Sandra Figueroa (1997), Atlas Etnográfico de la Cuenca Alta del Río Lerma, Tomo IV, Gobierno del Estado de México, Toluca, México.

Valenzuela, Alejandra y Héctor Robles Berlanga (1996), "Presencia de la mujer en el campo mexicano", Estudios Agrarios, Procuraduría Agraria, México, 5: 31-63. 
Zuloaga Albarrán, Alberto y Roberto Pérez Cerón (1996), “Generación y transferencia de tecnología agropecuaria: perspectivas y propuestas", en Posibilidades para el desarrollo tecnológico en el campo mexicano, tomo II, Instituto de Investigaciones Económicas-Programa Universitario de Alimentos-Centro para la Innovación Tecnológica, UNAMCambio xxi, Colección La estructura económica y social de México, México, pp. 33-60.

Recibido: 20 de septiembre de 2005. Reenviado: 14 de marzo de 2006. Aceptado: 4 de abril de 2006.

María Estela Orozco Hernández. Doctora en geografía por la Universidad Nacional Autónoma de México. Investigadora de la Facultad de Planeación Urbana y Regional y miembro del Sistema Nacional de Investigadores por la Universidad Autónoma del Estado de México. Sus líneas de investigación son los estudios urbanos y regionales. Entre sus publicaciones están: "Organización socioeconómica y territorial en la región del Alto Lerma”, Investigaciones Geográficas, Boletín del Instituto de Geografía, unAm, núm. 1, vol. 53, 2004; Atlas agrario ejidal del estado de México, UAEM, 2004; "Evaluación diagnóstica para el ordenamiento territorial de la Cuenca Alta del Río Lerma, México", Actas Latinoamericanas de Varsovia; Universidad de Varsovia, vol. 27, 2004; "Articulación de economías domésticas al desarrollo regional del Alto Lerma", Papeles de Población, UAEM, núm. 46, 2005; "Escenarios interpretativos, tendencias en la transformación de espacios rurales y periféricos de la zona metropolitana de la ciudad de Toluca", Investigaciones Geográficas, Boletín del Instituto de Geografía, unAM, vol. 60, 2006. Profesora de la maestría en Estudios Urbanos y Regionales y maestría y licenciatura en Ciencias Ambientales, UAEM.

María Teresa Sánchez Salazar. Doctora en geografía, investigadora del Instituto de Geografía, y miembro del Sistema Nacional de Investigadores por la Universidad Nacional Autónoma de México. Sus líneas de investigación son: geografía de los energéticos, cambios territoriales, y ordenamiento territorial. Entre sus publicaciones están: "Istmo de Tehuantepec: un espacio geoestratégico bajo la influencia de intereses nacionales y extranjeros. 
Éxitos y fracasos en la aplicación de políticas de desarrollo industrial (1820-2002)”, Investigaciones Geográficas, Boletín del Instituto de Geografía, UNAM, 2002; "La inversión privada en el sector eléctrico en México: su marco institucional y estructura territorial”, Investigaciones Geográficas, Boletín del Instituto de Geografía, unAM, núm. 54, 2004; "La experiencia mexicana en la elaboración de los Programas Estatales de Ordenamiento Territorial. Diagnóstico, problemática y perspectivas desde el punto de vista de la participación del Instituto de Geografía de la UNAM", Investigaciones Geográficas, Boletín del Instituto de Geografía, unAM, núm. 53, 2004. Proyectos: "Temas selectos de geografía de México", de 1998 a 2005; "Industria petrolera y cambios territoriales en el marco de la globalización económica”, 1998 a 2003; "Procesos territoriales asociados a la industria minerometalúrgica en México”, 1996 a la fecha; "Metodología para la elaboración de Programas Estatales y Mesorregionales de Ordenamiento Territorial", de 2001 a 2004; "Programa de Ordenación del Territorio del Estado de Jalisco”, de 2004 a 2005. Profesora de la maestría y licenciatura en Geografía, UNAM. 